\title{
Inferior Pubic Ramus
}

National Cancer Institute

\section{Source}

National Cancer Institute. Inferior Pubic Ramus. NCI Thesaurus. Code C132392.

The portion of the pubic ramus that lies between the superior pubic ramus and the inferior ramus of the ischium. 